\title{
Retroperitoneal teratoma as first sign of Klinefelter's syndrome
}

\author{
S Hachimi-Idrissi, S Desmyttere, A Goossens, B Desprechins, J Otten
}

\begin{abstract}
A 5 month old boy with a retroperitoneal teratoma was found to have a $47 \mathrm{XXY}$ karyotype indicating Klinefelter's syndrome. This observation suggests that patients with the syndrome may be at risk of germinal tumours in sites other than those usually reported (mediastinum, brain, and testes).

(Arch Dis Child 1995; 72: 163-164)
\end{abstract}

Keywords: Klinefelter's syndrome, teratoma.

Klinefelter's syndrome is a well documented syndrome of sex differentiation in male patients. It is a frequent cause of male hypogonadism with an incidence of one in 600 . It is usually characterised by the $47 \mathrm{XXY}$ genotype and typical clinical features, ${ }^{1}$ and the diagnosis is usually suspected during adolescence. Reviews of the case reports have suggested that Klinefelter's syndrome predisposes to the occurrence of germinal tumours in particular sites, mostly the mediastinum, ${ }^{2}$ with a relative incidence by site quite different from that known for the germinal tumours diagnosed in subjects without the syndrome. ${ }^{3}$ We report the first described case of a retroperitoneal teratoma in an infant with Klinefelter's syndrome and hypothesise that the particular distribution of germinal tumour sites in patients with the syndrome could possibly result from a bias in diagnostic search for Klinefelter's syndrome in

University Hospital, Free University of Brussels, Brussels, Belgium, Department of Paediatrics S Hachimi-Idrissi $S$ Desmyttere J Otten

Department of

Pathology

A Goossens

Department of Radiology

B Desprechins

Correspondence and reprint requests to: Dr S HachimiIdrissi, Department of
Paediatrics, AZ-Kinderen Paediatrics, AZ-Kinderen B-1090 Brussels, Belgium. Accepted 5 October 1994

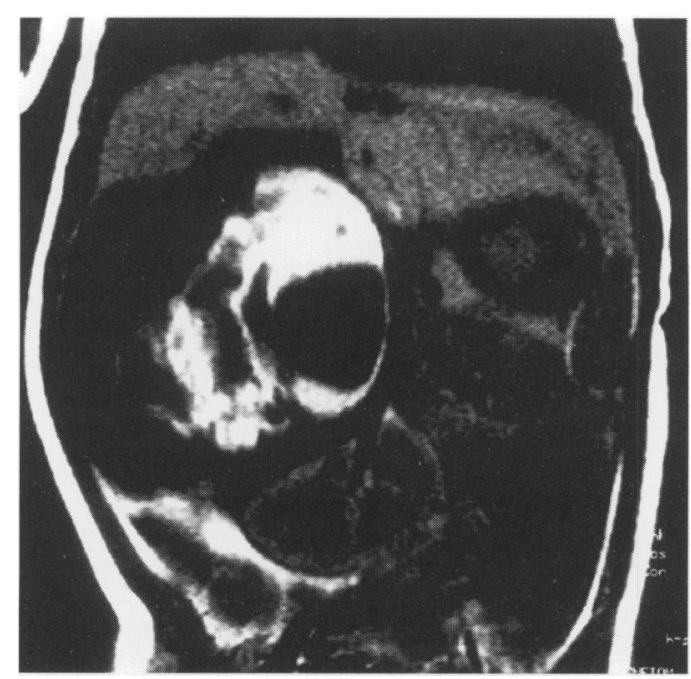

Figure 1 Precontrast T1 weighted image on nuclear magnetic resonance showing a large well circumscribed abdominal mass clearly separated from the right kidney, which is displaced inferiorly and medially. Liver compression by the tumour mass is seen. The mass exhibits a heterogeneous intensity pattern with $T 1$ (and T2) signal characteristics indicating the presence of cystic areas, solid components, and fat. patients with tumour sites traditionally considered as typical for this association.

\section{Case report}

A 5 month old boy was admitted with a history of crying and constipation of two weeks' duration. The patient was well and the physical examination was normal except for the presence of an abnormal mass in the right upper quadrant of the abdomen.

Ultrasonography showed a large well circumscribed right intra-abdominal mass. The mass exhibited a very heterogeneous echogenicity compatible with the presence of cystic and solid areas, calcified foci, and fat. On nuclear magnetic resonance the dimensions of this retroperitoneal tumour were $11 \mathrm{~cm}, 9 \mathrm{~cm}$, and $8 \mathrm{~cm}$ (fig 1). The tumour was totally removed. Histological examination demonstrated a great variety of tissue components of which neurological elements resembling brain tissue were the most prominent. The tumour also contained skin, hair, and sebaceous glands. Different types of well differentiated epithelia, including pigmented retinal epithelium and gastrointestinal tract tissues could be identified. Islands of cartilage and well organised bone were distributed throughout the tumour. Scanty areas of primitive neuroectodermal elements could be discerned (fig 2). Ependymal-like cells forming rosettes with a small lumen were present. A grade I immature teratoma was diagnosed from the pathology. A chromosome analysis on blood lymphocytes showed a $47 \mathrm{XXY}$ karyotype in all metaphases.

This patient is to our knowledge the first in whom Klinefelter's syndrome has been reported to be associated with a germinal tumour in the retroperitoneal space.

\section{Discussion}

Although the incidence of Klinefelter's syndrome is relatively high $(1 / 600)$, the association of this syndrome with germinal tumours is considered to be more than coincidental, the more so as the distribution of reported germinal tumour sites is very different in patients with Klinefelter's syndrome and in the general population respectively. ${ }^{3}$ If it were pure coincidence, one would have expected a preponderance of gonadal germinal tumours to have been reported in Klinefelter's syndrome as this site is by far the most frequent within the age range in which the association has been reported so far. $^{4}$

Diagnosis of Klinefelter's syndrome may be difficult. It usually remains unsuspected before puberty and even in adolescence or 

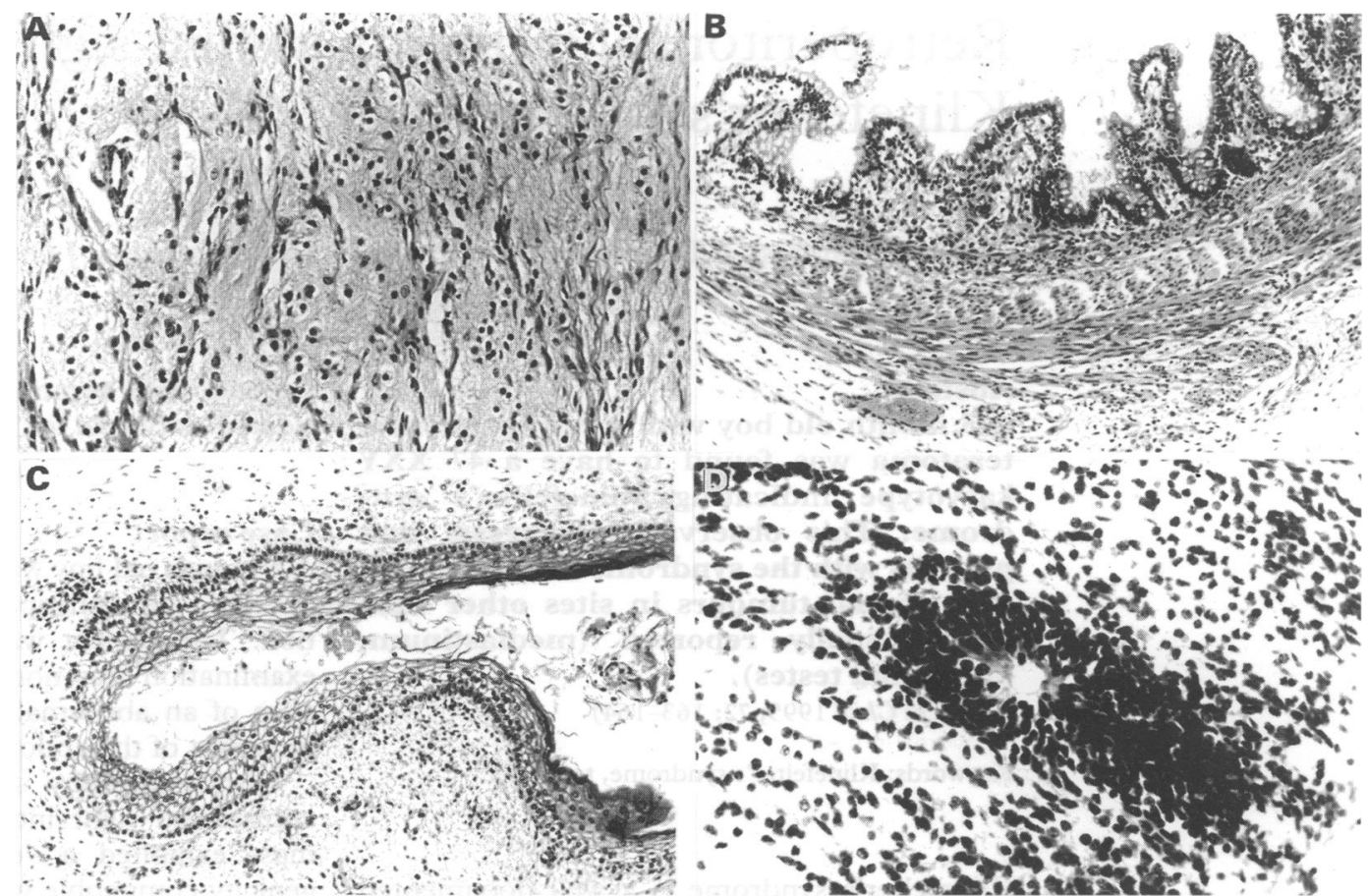

Figure 2 Teratoma showing representative types of somatic tissues (haematoxylin and eosin stain): (A) differentiated neuroglia ( $\times 250)$; (B) alimentary tract tissues ( $\times 120)$; (C) focally keratinised squamous epithelium $(\times 120)$; and $(D)$ immature neuroepithelium with a rosette-like arrangement $(\times 250)$.

in adulthood it may remain unrecognised. Therefore, the association of a germinal tumour with the syndrome is not always evident and can only be ascertained by a karyotype. This was the case in our patient who was too young to express any clinical signs of Klinefelter's syndrome. Therefore, although the preponderance of mediastinal sites of germinal tumours in patients with the syndrome might be real, it could also be factitious and result from a more frequent search for cytogenetic abnormalities when that particular site is involved. In the first three reports of germinal tumours in patients with Klinefelter's syndrome the tumours were mediastinal. 235

These reports have perhaps biased doctors into thinking that germinal tumours in Klinefelter's syndrome occur exclusively in the mediastinum and might have led to a relative underdiagnosis of the syndrome when associated with germinal tumours in other sites. An accurate assessment of the incidence and of the clinical features of germinal tumours associated with Klinefelter's syndrome would require a systematic karyotyping of all male patients with such tumours. As in our patient, this would also allow diagnosis of Klinefelter's syndrome at an early age at which usual signs of the syndrome are not yet expressed.

1 Park GS. Current concepts in genetics. Sex chromosome disorders. N Engl f Med 1976; 294: 706-8.

2 Schimke RN, Madigan CM, Silver BJ, Fabian CJ, Stephens RL. Choriocarcinoma, thyrotoxicosis, and the Klinefelter's syndrome. Cancer Genet Cytogenet 1983; 9: 1-8.

3 Curry WA, McKay CE, Richardson RL, Greco FA. Klinefelter's syndrome and mediastinal germ cell neoKlinefelter's syndrome and media
plasms. $₹$ Urol 1981; 125: 127-9.

4 plasms. F Urol 1981; 125: 127-9. teratomas in childhood. In: Finegold $M$, Benington J, eds. Pathology of neoplasia in children and adolescents. Major problems in pathology. Philadelphia: WB Saunders, 1986: 282-312.

5 Dexeus FH, Logothetis CJ, Chong C, Sella A, Ogden S. Genetic abnormalities in men with germ cell tumours. $\mathcal{f}$ Urol 1988; 140: 80-4. 